\title{
Esthetic Restoration of Two Severely Decayed Maxillary Central Incisors: A Case Report
}

\author{
Saafi J*, Debbabi I, Chakroun M, Harzallah BH and Cherif M \\ Faculty of Dentistry, Avicenna Street Monastir, Tunisia
}

*Corresponding author: Saafi J, Faculty of Dentistry, Avicenna Street Monastir, Tunisia, Tel: +966549694345, +21623407311 E-mail: saafi_jilani@yahoo.fr

Citation: Saafi J, Debbabi I,Chakroun M, Nouira Z, Harzallah BH, Cherif M (2017) Esthetic Restoration of Two Severely Decayed Maxillary Central Incisors: A Case Report. J Oral Health Dent Sci 1: 104

Article history: Received: 29 May 2017, Accepted: 10 July 2017, Published: 12 July 2017

\begin{abstract}
Materials selection is the second in the series on crowns and other extra-coronal restorations. Some of us are less than inspired by dental materials science. Restoration of an anterior root-filled tooth with little remaining coronal tooth-tissue can use a post to retain a core enabling definitive restoration. Fiber posts present good biomechanical behavior because of their elastic modulus. It is similar to that of dentine. Treatment failure occurs through decementation rather than because of root fracture as it occurs with metal posts.

In this article, a 25 -year female patient was referred to our department of fixed prosthodontics for an esthetically compromised smile due to severely decayed central incisors and she requested esthetic smile rehabilitation. The two incisors were restored with fiber post composite and CAD/CAM zirconia based ceramic crowns as extra-coronal restoration.
\end{abstract}

Keywords: Esthetic smile; Fiber post; Resin composite; Zirconia; CAD/CAM; Ceramic crown

\section{Introduction}

Today, patients are increasingly interested in metal-free restoration. Restoration of an anterior root-filled tooth with little remaining coronal tooth tissue can use a post to retain a core enabling definitive restoration. Post material has been, until recently, primarily metal--be it cast or prefabricated. Currently, fiber-posts are promoted as being advantageous due to a favorable failure mechanism which may protect the root from fracture [1]. Endodontic posts are necessary to provide adequate retention and support when no sufficient remaining structure is available to retain the core. There are different materials and techniques to construct post-andcore, but there is no consensus about which one promotes better stress distribution on the remaining tooth structure [2]. The new ceramics used for final crowns by CAD/CAM technique associate aesthetic and good mechanical qualities, biocompatibility, and accurate marginal fit and low invasive preparation.

\section{Case presentation}

A 25-year healthy female patient presented to the department of fixed prosthodontics at the dental clinic of Monastir (Tunisia) for restoring her maxillary central incisors teeth. She complained about anterior teeth fracture and asked for an aesthetic, pleasing and natural appearing smile with harmony between anterior teeth. She also requested a functional restoration during phonation and mastication.

Dental history did not reveal any past present symptom. The fracture of the central incisors was related to a trauma.

Intra-oral examination showed an average lip line exposing the maxillary teeth and only the interdental papillae as well as severe cervical decay with significant substance loss. The anterior guide is non functional with posterior interferences (Figure 1).

Central incisors were severely decayed and endodontically treated (the periapical X-ray is unfortunately not given in this article). The level of remaining teeth is still in supra-gingival situation which is favorable for a bonding technique as an alternative to cast post-and-core.

The treatment protocol should be as conservative as possible with less reduction of the remaining teeth structure and greater esthetics and longevity [3]. 


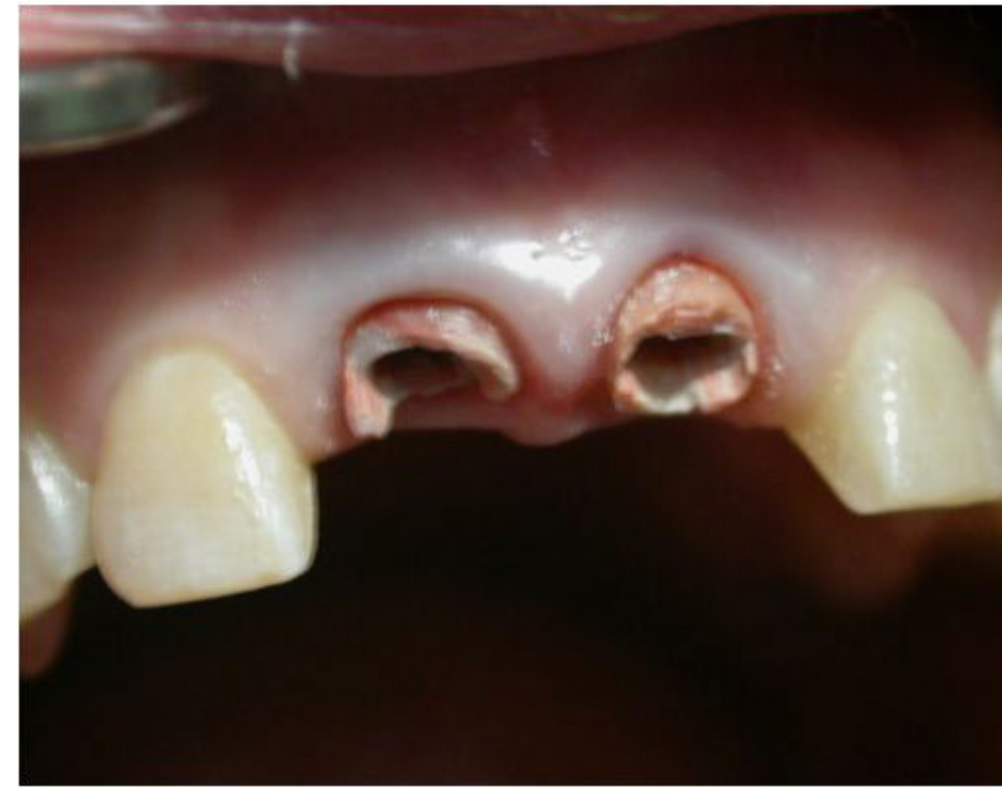

Figure 1: Intra-oral view

Zirconia crowns were indicated as all ceramic esthetic restoration because it has been considered a desirable substitute substructure for a bi-layer crown due to its high strength properties and more tooth-like appearance [4].

There are certain recommendations for preparing teeth using Zirconia as a substrate. The shared preparation principles in the anterior and posteriors regions for all systems (i.e., single-unit and FPD abutment) include an incisal/occlusal reduction of 1.5mm to $2 \mathrm{~mm}$ [5]. These are the minimal amounts of reduction that are acceptable. Increasing the amount of incisal reduction in the anterior region to $2 \mathrm{~mm}$ gives the dental technician more room to develop the esthetics.

Subgingival margins are often required for biologic, mechanical, or esthetic reasons. Several investigations have demonstrated that their use is associated with adverse periodontal reactions, such as inflammation or recession [6]. Subgingival margins do influence the periodontal soft tissue response. Statistically significant difference exists between feather edge and chamfer finishing lines in regard to bleeding on probing and gingival recession. Subgingival margins should be carefully selected, especially when feather edge finishing line is utilized [7].

The preparation was achieved with using flat end tapered diamond bur and extended in the sulcus to cover all the discolored abutments (Figure 2).

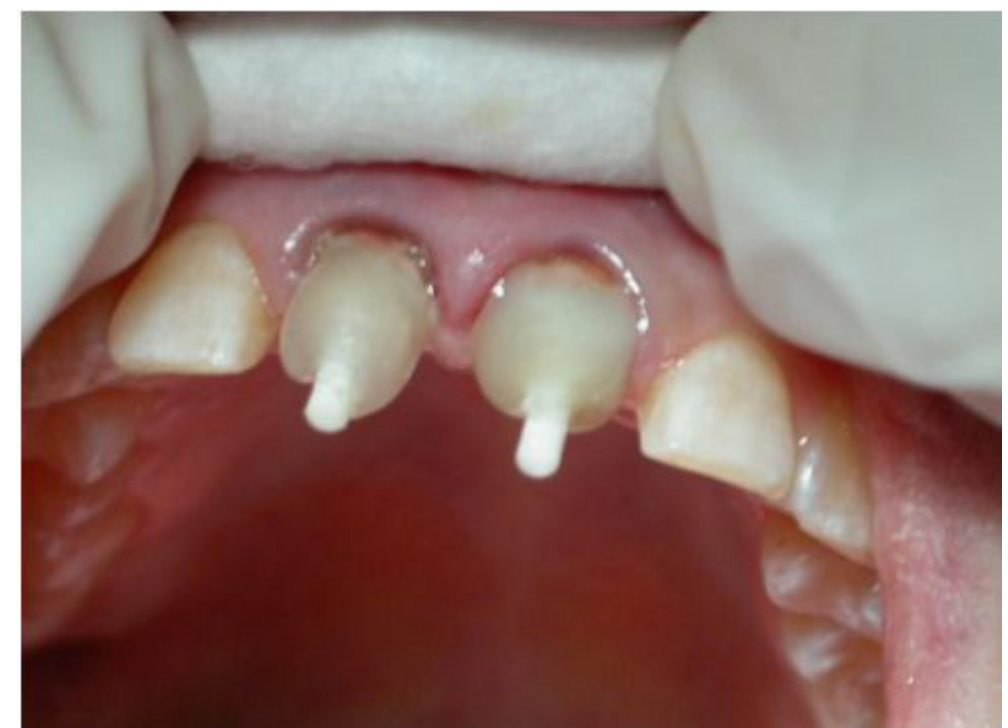

Figure 2: Build-up technique by fiber reinforced posts composite resin

The central incisors have been restored by build-up technique with two fiber reinforced posts composite resin.

Most CAD/CAM and copy milling systems recommend that the minimum axial wall reduction for anterior crowns be $1 \mathrm{~mm}$ to 1.5 $\mathrm{mm}$, and $1 \mathrm{~mm}$ to $2 \mathrm{~mm}$ for posterior crowns. The total occlusal convergence angle can range between $4^{\circ}$ to $6^{\circ}[8]$.

An optical scanner requires a minimum of a $4^{\circ}$ occlusal convergence angle to adequately read the margin of the master die [7,9]. 
Parallel walls distort most scanners and should be avoided. A silicone index of the mock-up study model can be used to verify the proper reduction.

The internal aspect of the margin should be either a rounded shoulder or a deep chamfer of at least $1 \mathrm{~mm}$ [9]. A 90 internal angle is contraindicated. The exit angle of the gingival margin should be a butt joint and lack any beveled edges (Figure 3 and 4 ).

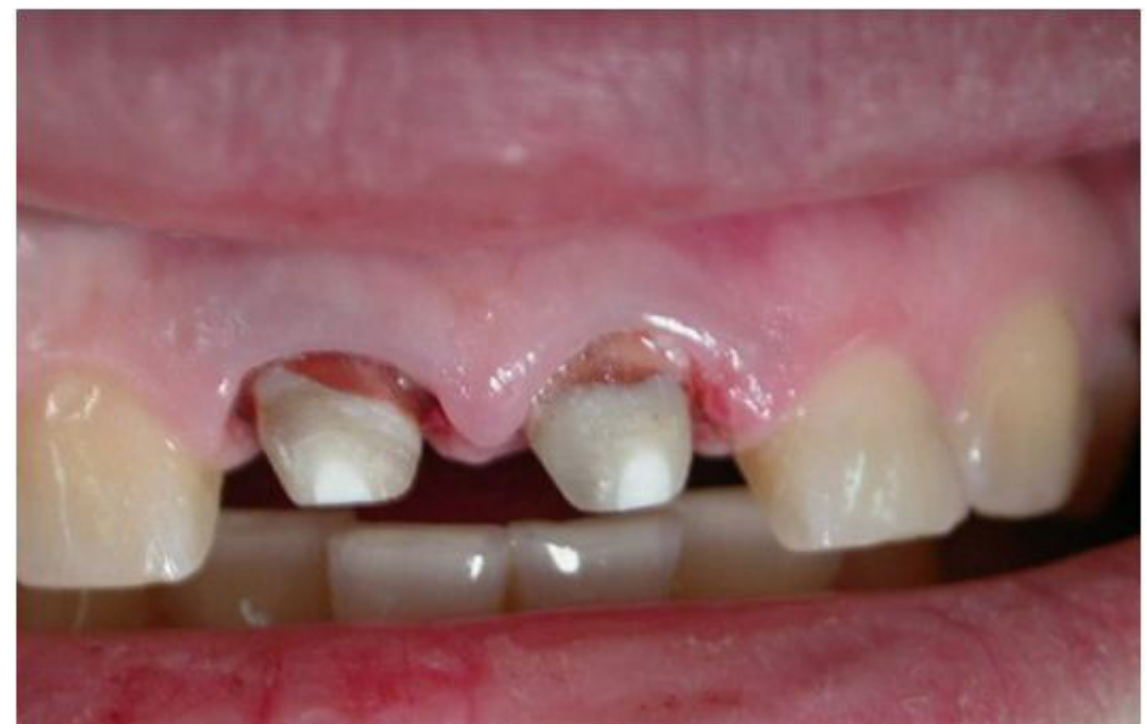

Figure 3: Final preparations

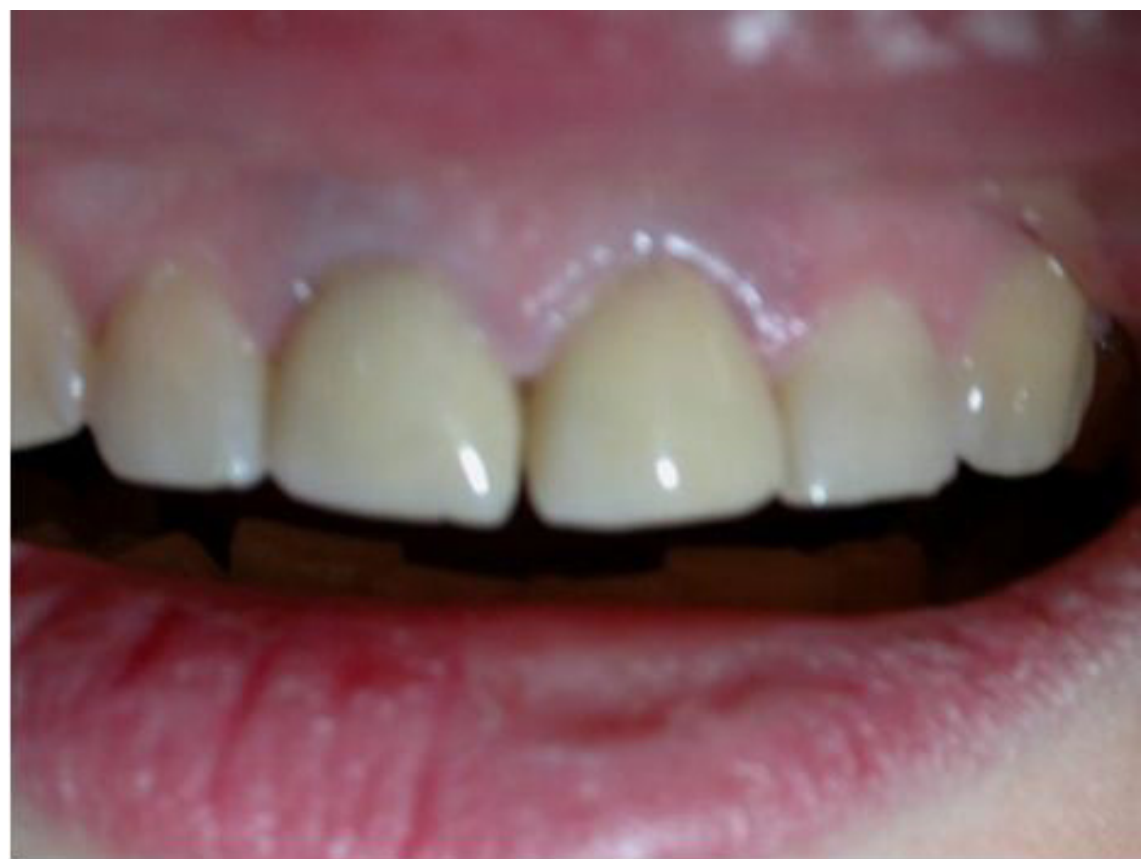

Figure 4: Temporary Prostheses

The temporary prosthesis was made in the laboratory by a resin with high aesthetic and mechanical properties. The sealing was carrying out by free eugenol cement. After an aesthetic evaluation (color, shape, size and position of teeth) and functional checking (anterior guidance, phonation), a final impression was taken using polyvinyl siloxane and sent to the laboratory. The shade selection was taken with shade guide Vitapan 3D Master-Vita. There the working cast was scanned and frameworks were manufactured with computer-aided manufacturing after the step of computer-assisted design using CAD/CAM indirect technique.

Fabricating zirconia single copings and frameworks involves the manipulation of a 3-D design on the computer screen, followed by the automated production by a computer-controlled milling machine [10]. There are three components to the CAD/CAM system: scanning, designing, and milling. All are usually housed at the laboratory (Figure 5).

Every zirconia framework always requires a try-in step to confirm fit, insertion retention, marginal integrity, and mostly the space left for cosmetic ceramic without omission of the shade appearance. Then, ceramic stratification was performed in the lab [11] (Figure 6).

In the clinic, zirconia ceramic crowns were tried again to verify esthetic, occlusion relationship and cemented using adhesive cement. 


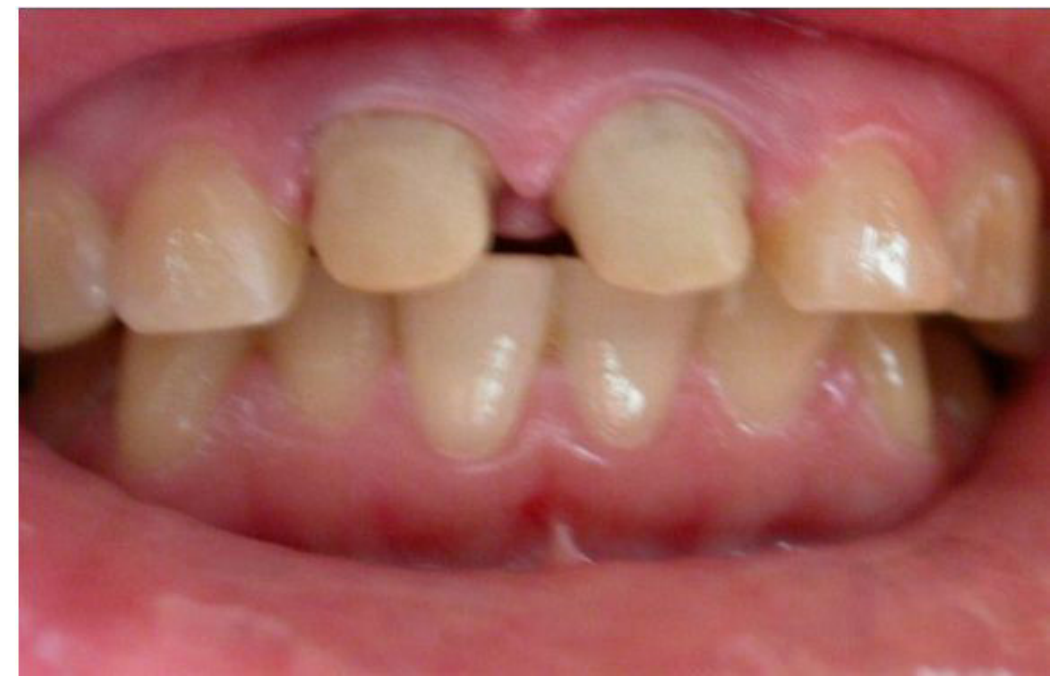

Figure 5: Trying zirconia frameworks

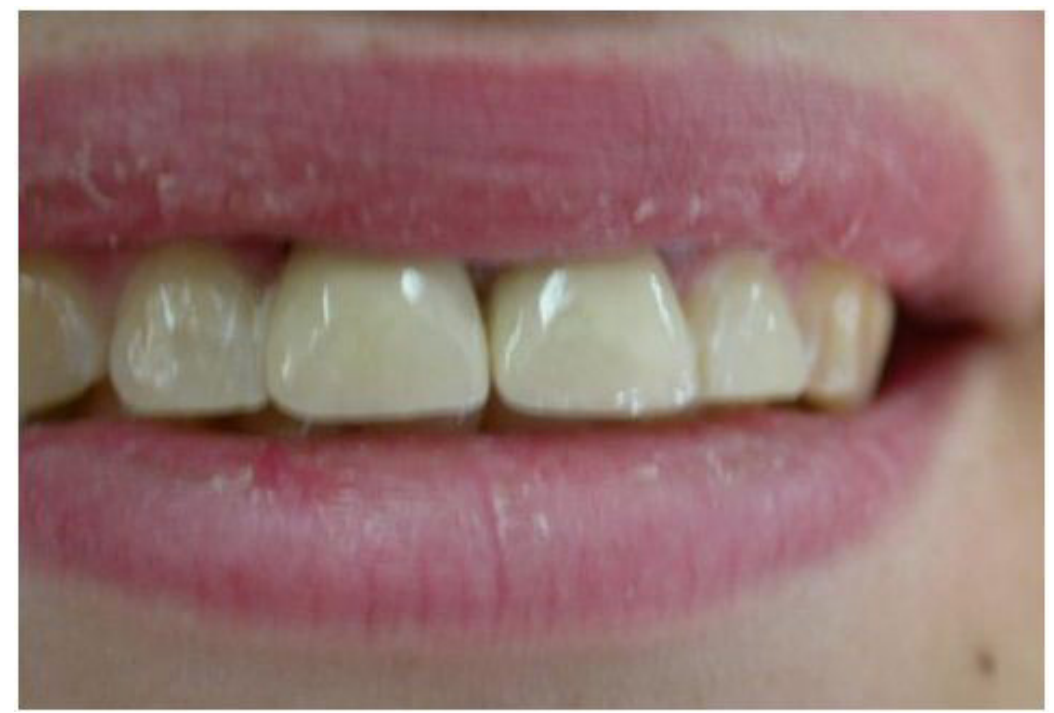

Figure 6: Extra-oral view after cementation with adhesive cement

\section{Discussion}

The rehabilitation of two severely decayed central incisors is a real clinical challenge. Teeth requiring endodontic treatment commonly have compromised a coronal tooth structure that often requires the use of an intraradicular post to retain the coronal restoration.

Currently, fiber-posts are promoted as being advantageous due to a favorable failure mechanism which may protect the root from fracture [1]. A meta-analysis study evaluated the effects of the remaining coronal tissue and post type on the fracture strength of incisors has concluded that the fracture strength did not differ among the post types evaluated. In the presence of remaining coronal structure, the fracture strength was higher in specimens with cast cores and posts [12].

A finite element study of teeth restored with post and core conducted by Upadhyaya V et al concluded that the highest amount of stress was in the cervical region. Fiber reinforced composite post (FRC) and composite resin core recorded minimal stresses within the post but the stresses transmitted to cervical dentin were more as compared to other systems. Minimal stresses in cervical dentine were observed where the remaining coronal dentin was strengthened by ferrule [13]. The position of the tooth in the arch, ferrule size, proximal contact, periodontal support and restoration type are survival prediction factors that should be considered when performing post-endodontic restoration [14].

The length of fiber post relined with resin composite did not influence fracture resistance, but thickness was an important factor for the restoration of endodontically treated teeth [15]. Teeth restored with cast post and cores present higher fracture strength than those reinforced with glass-fiber posts. An increased post-thickness does not increase the fracture strength. Glass-fiber posts lead to less severe fractures [16].

The majority of the practitioners used fiber posts. In terms of fracture, this may be compared favorably with cast-metal post and core. Although little evidence in the literature validates this claim [17]. Finish line selection should be based on the type of crown/ 
retainer, esthetic requirements, ease of formation, and personal experience. Esthetic requirements and tooth conditions determine finish line locations relative to the gingiva, with a supragingival location being more acceptable [18].

Nowadays, all-ceramic systems are a focus of interest, because they offer aesthetic results that may be difficult to achieve with metal-ceramic systems [19].

No differences were found in the clinical marginal fit of zirconia crowns fabricated from either digital impressions compared with polyvinyl siloxane impressions (PVS). Furthermore, patients' satisfaction with digital impressions was significantly higher than with conventional impressions [20]. Although both direct and indirect digitalization facilitates the fabrication of single crowns and three-unit FDPs with clinically acceptable marginal fit. Besides, according to a meta-analysis study conducted by Tsirogiannis P et al, no significant difference was observed regarding the marginal discrepancy of single-unit ceramic restorations fabricated after digital or conventional impressions [21].

On the other hand, in their study of two different resin-modified, glass-ionomer cements, Huang et al found extensive hygroscopic expansion [22]. Sindel et al evaluated the effects of various luting materials on the crack formation of all ceramic crowns. They concluded that the hygroscopic expansion of resin-modified, glass-ionomer cement led to failure of all -ceramic crowns [23].

Tribochemical silica coating and the application of a 10-methacryloyloxydecyl dihydrogen phosphate monomer(MDP)-containing bonding/silane coupling agent mixture has been shown to increase the shear bond strength between zirconium -oxide ceramic and resin luting agent (Panavia F 2.0 and ED primer A\&B, Kuraray America, Inc, New York, NY; RelyX ; and RelyX Unicem ) upon removal stress application [24].

\section{Conclusion}

Esthetic and functional rehabilitation of two severely decayed central incisors are a real clinical challenge. Teeth requiring endodontic treatment commonly have compromised a coronal tooth structure that often requires the use of an intraradicular post to retain the coronal restoration. Using the fiber post and composite core is a suitable and economical alternative restoration technique. In dental ceramics, zirconia has proven to be a durable, reliable framework material. Used in combination with CAD/ CAM technology, zirconia enables the fabrication of esthetic all-ceramic restorations in all areas of the mouth $[25,26]$.

\section{References}

1. Lancaster PE (2015) Restorative Case Report: Flexibility of Fibre-Posts. Eur J Prosthodont Restor Dent 23: 85-90.

2. Bosso K, Gonini Júnior A, Guiraldo RD, Berger SB, Lopes MB (2015) Stress generated by customized glass fiber posts and other types by photoelastic analysis. Braz Dent J 26: 222-7.

3. Asbia S, Saafi J (2017) Smile design (Review). Africain journal of dentistry and implantology No 9: 11-28.

4. Fasbinder DJ (2010) Zirconia Restorations: Perception or Evidence? Inside dentistry 6.

5. Raigrodski AJ (2003) Clinical and laboratory considerations for the use of CAD/CAM Y-TZP-based restorations. Pract Proced Aesthet Dent 15: 469-76.

6. Paniz G, Nart J, Gobbato L, Mazzocco F, Stellini E, et al. (2017) Clinical Periodontal Response to Anterior All-Ceramic Crowns with Either Chamfer or Featheredge Subgingival Tooth Preparations: Six-Month Results and Patient Perception. Int J Periodontics Restorative Dent 37: 61-8.

7. Paniz G, Nart J, Gobbato L, Chierico A, Lops D, et al. (2016) Periodontal response to two different subgingival restorative margin designs: a 12-month randomized clinical trial. Clin Oral Investig 20: 1243-52.

8. Doyle MG, Munoz CA, Goodacre CJ, Daniel FL, Keith MB (1990) The Effect of Tooth Preparation Design on the Breaking Strength of Dicor Crowns: Part 2. Int J Prosthodont 3: 241-8.

9. Boudrias P (2005) The Yttrium Tetragonal Zirconia Polycrystals (Y-TZP) Infrastructure: The New Chapter in the Search for a Metal Framework Replacement. Dent J Quebec 42: 172-6.

10. Tinschert J, Natt G, Hassenpflug S, Spiekermann H (2004) Status of current CAD/CAM technology in dental medicine. Int J Comput Dent 7: 25-45.

11.Anissa BM, Chakroun M, Hadyaoui D, Nouira Z, Cherif M (2017) Zirconia Based Crowns for Esthetic Rehabilitation of Severely Discolored Teeth: A Case Report. J Oral Health Dent Sci 1: 1-4.

12. Figueiredo FE, Martins-Filho PR, Faria-E-Silva AL (2015) Do metal post-retained restorations result in more root fractures than fiber post-retained restorations? A systematic review and meta-analysis. J Endod 41: 309-16.

13. Upadhyaya V, Bhargava A, Parkash H, Chittaranjan B, Kumar V (2016) A finite element study of teeth restored with post and core: Effect of design, material, and ferrule. Dent Res J (Isfahan) 13: 233-8.

14. Bru E, Forner L, Llena C, Almenar A (2013) Fibre post behaviour prediction factors. A review of the literature. J Clin Exp Dent 5: e150-3.

15. Farina AP, Weber AL, Severo Bde P, Souza MA, Cecchin D (2015) Effect of length post and remaining root tissue on fracture resistance of fibre posts relined with resin composite. J Oral Rehabil 42: 202-8.

16. Bacchi A, dos Santos MBF, Pimentel MJ, Caetano CR, Sinhoreti MAC, et al. (2013) Influence of post-thickness and material on the fracture strength of teeth with reduced coronal structure. J Conserv Dent 16: 139-43.

17. Ahmed SN, Donovan TE, Ghuman T (2017) Survey of dentists to determine contemporary use of endodontic posts. J Prosthet Dent 117: 642-5.

18. Goodacre CJ, Campagni WV, Aquilino SA (2001) Tooth preparations for complete crowns: an art form based on scientific principles. J Prosthet Dent 85: 363-76.

19. Legros C, Vanheusden A (2006) [All-ceramic peripheral restorations: crowns and bridges]. Rev Belge Med Dent 61: 30-46. 
20. Ahrberg D, Lauer HC, Ahrberg M, Weigl P (2016) Evaluation of fit and efficiency of CAD/CAM fabricated all-ceramic restorations based on direct and indirect digitalization: a double-blinded, randomized clinical trial. Clin Oral Investig 20: 291-300.

21. Tsirogiannis P, Reissmann DR, Heydecke G (2016) Evaluation of the marginal fit of single-unit, complete-coverage ceramic restorations fabricated after digital and conventional impressions: A systematic review and meta-analysis. J Prosthet Dent 116: 328-35.

22. Huang C, Kei LH, Wei SH, Cheung GS, Tay FR, et al. (2002) The influence of hygroscopic expansion of resin-based restorative materials on artificial gap reduction. J Adhes Dent 4: 61-71.

23. Sindel J, Frankenberger R, Krämer N, Petschelt A (1999) Crack formation of all-ceramic crowns dependent on different core build-up and luting materials. J Dent 27: 175-81.

24. Atsu SS, Kilicarslan MA, Kucukesmen HC, Aka PS (2006) Effect of zirconium-oxide ceramic surface treatments on the bond strength to adhesive resin. J Prosthet Dent 95: 430-6.

25. Giordano R (2012) Zirconia: a proven, durable ceramic for esthetic restorations. Compend Contin Educ Dent 33: 46-9.

26. Giordano R, Sabrosa CE (2010) Zirconia: material background and clinical application. Compend Contin Educ Dent 31: 710-5. 